\title{
Desenvolvimento da Plataforma Raps-Salus: Rede de Atenção Primária a Saúde
}

\author{
João Rabelo de Araújo Filho', Paulo Ezequiel Dias dos Santos² \\ 12 Universidade Tiradentes (UNIT) \\ Aracaju-SE - Brasil \\ joao.filhodsouunit.com.br, paulo.ezequieldsouunit.com.br
}

\begin{abstract}
This article aims to describe the development of an application, an API and a WEB application that refers to the mapping of the primary health care network, using data from the Family Health Program (FHP). From there, the application was built using the NET Core, IONIC and Angular frameworks. Key elements for the platform were available: priority groups of primary care, such as status, description and geolocation. The platform aimed to facilitate the management made by health professionals, in addition to synchronization and integrality with external applications.
\end{abstract}

Resumo. Esse artigo objetiva descrever o desenvolvimento de um aplicativo, uma Web API e uma aplicação WEB de referência ao mapeamento da rede de atenção primária a saúde, utilizando fundamentalmente dados do Programa de Saúde da Família (PSF). A partir disso, o aplicativo foi construído utilizando os frameworks NET Core, IONIC e Angular. Disponibilizaram-se elementos chaves para a plataforma que foram: os grupos prioritários da atenção primária, como seu status, descrição e geolocalização. A plataforma visou facilitar a gestão feita pelos profissionais de saúde, além da sincronização e integralidade com aplicações externas.

\section{Introdução}

A adoção Sistema Único de Saúde e suas políticas públicas têm como obrigatoriedade a implementação da atenção primária a saúde (APS) [BRASIL 2017], que é o conjunto de ações no âmbito individual e coletivo, que abrangem a promoção e a manutenção da saúde. O sistema sofre atualmente com a inversão de prioridades e com a má comunicação entre a comunidade e instituições, criando uma pirâmide entre setores, que causa atraso nos diagnósticos, que leva sofrimento, hospitalizações e morte com custos totais altos, além de um baixo impacto na saúde e menor satisfação do paciente. Esses pontos justificam o presente trabalho, que pretende relatar a construção de uma plataforma digital de referência na atenção primária à saúde, objetivando a transformação da atual pirâmide em uma rede com uma maior inteligibilidade e monitoramento nas linhas de comunicação e criando elos para uma melhor coordenação com a coleta e sincronização de dados.

\section{Descrição do Aplicativo 'RAPS-Salus'}

A plataforma RAPS-Salus (Rede de Atenção Primária a Saúde-Salus) tem esse nome devido a deusa romana que representa a promoção da saúde. A plataforma traz suas funcionalidades baseadas nos quatro princípios da APS [World Health Organization 2008], na qual o primeiro é a porta de entrada ao sistema, que é realizado através do aplicativo móvel com cadastro do paciente através do profissional de saúde, usando a 
geolocalização e informações como nome e sua condição de saúde, o segundo e terceiro princípios são continuidade e coordenação que são feitos através do monitoramento, filtragem e atualização do status dos pacientes através do aplicativo móvel ou da aplicação web que estará disponível na Unidade Básica de Saúde (UBS) e o último que é integralidade que é feito pela a portabilidade da API do RAPS-Salus a integrações com sistemas terceiros como de uma maternidade e notificações realizadas através de canais de eventos, tendo a informações de referência e contrarreferência do paciente.

A arquitetura da plataforma é dividida em três aplicações a primeira é o aplicativo móvel feito com o framework IONIC, onde é possível fazer o cadastro, atualização e visualização dos pacientes usando como plug-in de mapeamento a Plataforma Google Maps. A segunda é uma aplicação web que será feita com o framework Angular, que possui as mesmas funcionalidades do móvel, mas oferece uma visão mais ampliada da rede. A terceira é uma Web API feito com o framework Net Core que centraliza todas as aplicações servindo como back-end, comunicação com o banco de dados, notificações de eventos utilizando a Plataforma Pusher, como também autorização e integração com aplicações externas, através do protocolo HTTPS.

\section{Contribuições Tecnológicas (Para a Sociedade e/ou Cidadania)}

A plataforma RAPS-Salus contribui com a identificação da população e suas condições de saúde, transformará o sistema de saúde em uma rede, que fortalece a entrada do paciente pela UBS, onde ocorre a promoção e prevenção da saúde, aumentando a probabilidade de identificar patologias, prescrever poucas intervenções invasivas e com as integrações dos recursos é possível um melhor uso desse serviços, evitando atrasos de exames, consultas e vacinas. Além disso, a equipe terá campanhas com impactos mais positivos, auxiliando as pessoas a navegarem nas complexas redes dos serviços de saúde.

\section{Conclusão}

Este artigo apresentou o desenvolvimento de uma plataforma para APS, denominado de RAPS-Salus. O desenvolvimento se baseou nos conceitos de mapeamento por geolocalização dos grupos prioritários do PSF que fundamenta a promoção e manutenção da saúde do indivíduo e da comunidade. A plataforma possui diversas funcionalidades úteis aos profissionais de saúde e gestores pois cria um mapeamento interativo, humanizado e com usabilidade. Como prosseguimento do trabalho, sugere-se a definição de novos atributos que atendam às necessidades de sincronização de dados e integralidade com aplicações externas, como base de dados para novos aplicativos.

\section{Referências}

PORTARIA No 2.436, DE 21 DE SETEMBRO DE 2017, Aprova a Política Nacional de Atenção Básica, estabelecendo a revisão de diretrizes para a organização da Atenção Básica, no âmbito do Sistema Único de Saúde (SUS). Disponível em: <http://bvsms.saude.gov.br/bvs/saudelegis/gm/2017/prt2436_22_09_2017.html>. Acesso em: 11 mar. 2019.

World Health Organization, "The world health report 2008: primary health care now more than ever”. Geneva: World Health Organization; 2008. 